\title{
A B2C AGRICULTURAL PRODUCTS SELF-DISTRIBUTION SYSTEM IN E-COMMERCE ENVIRONMENT
}

\author{
Han Gao \\ Department of Economic Management, Xi'an Vocational and Technical College, Xi'an, Shaanxi, 710077, China \\ gaohan69xz@126.com
}

\begin{abstract}
With the advent of Internet plus age, agricultural products home delivery mode has been concerned more and more. In this study, an optimized e-commerce distribution system was designed against the problems existing in the traditional agricultural products distribution process. The distribution structure and technology, operation process and profit model were analyzed based on business to customer (B2C) mode. Moreover the self-distribution system was optimized. As to the problem of distribution route, the concept of time window was added for restriction, hypothesis was proposed, and the role of saving algorithm for distribution route was analyzed. An example was demonstrated to verify that adding time window constraint saving algorithm into B2C mode based self-distribution system could optimize distribution route and enhance distribution efficiency. The application of the algorithm can save distribution cost and improve economic benefits.
\end{abstract}

Keywords: B2C Mode, Distribution Route, Time Window, E-commerce Environment.

\section{Introduction}

With the development of e-commerce, the mode of market trade has gradually changed from the traditional customer-to-customer (C2C) e-commerce mode to the business-to-customer (B2C) e-business mode. B2C trade process costs low and moreover is featured by concise flow and obvious temporalspatial traits.

B2C is a mode which directly sells products or services to customers based on network platform; a series of consumption behaviors such as online purchase and payment can be realized via Internet. Zhang et al. [1] studied the integrated online scheduling of order batching and delivery in B2C ecommerce, put forward several new rules based solutions, and evaluated the solutions through a series of experiments. They found that the new algorithms could lead to a significant increase in the number of orders. Höglund and Wikman [2] developed a simple model to evaluate the influence of B2C sharing on consumers.

They found that goods were utilized more when they were shared, introducing a sharing market might decrease consumption of new goods, despite enabling new consumers to enter the market, and consumer surplus increased when the sharing price was lower than the ownership price. In the aspect of B2C cost, products can be distributed to more customers via Internet with less cost.
Distribution of agricultural products based on B2C mode can reduce the middle links and cost and increase sales, but there are usually many problems in the link of distribution.

Aiming at the problems of high cost and unreasonable layout of the self built logistics system of B2C e-commerce company, Li et al. [3] proposed an optimization plan of B2C logistics distribution. A mathematical model was established based on various costs, taking into account economies of scale and standard service levels. A hybrid genetic simulated annealing algorithm was proposed to solve the problem of NP-hard complexity of the model. To save distribution cost and improve economic benefits, distribution routes were optimized based on B2C mode for agricultural products distribution system platform in this study.

\section{The Traditional Logistics Distribution of Agricultural Products}

Figure 1 shows that the traditional logistics distribution of agricultural products involves many links. Agricultural products which are purchased by customers may arrive destinations after multiple trade links [4]. Agricultural products may get bad during transportation because of the redundant logistics links and short refreshing time of products, which will cause loss to merchants; as a result, transportation cost and loss will be added to the purchasing price. 


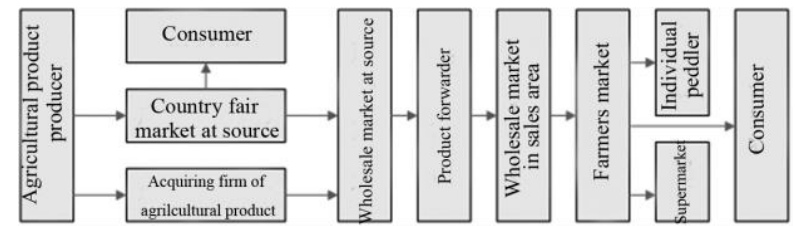

Figure 1: The traditional logistics distribution mode of agricultural products

The traditional agricultural products logistics distribution has the following disadvantages [5]. Firstly, the long agricultural products supply chain and lack of efficient transportation equipment in most areas result in high damage rate of agricultural products. Secondly, China's current agricultural logistics distribution system is still not perfect, the relevant interests parties in the distribution process are lack of instant communication, and organization and management are also not coordinated, resulting in inefficient logistics and distribution. Thirdly the less developed areas fail to adjust the agricultural production in time and scientifically because of the lack of network or other means which can help understand market information. As a result, production and consumption are unbalanced, which is shown as insufficient transportation volume in the peak season of agricultural products and surplus transportation volume in the weak season.

\section{Analysis on B2C}

With the rapid development of Internet, new electronic commerce has begun to appear and has gradually replaced the traditional business mode because of its advantages of convenience and high efficiency. To solve problems existing in the traditional distribution logistics of agricultural products, $\mathrm{B} 2 \mathrm{C}$ mode in e-commerce was applied to optimize the distribution logistics of agricultural products.

\section{B2C mode based distribution structure}

Figure 2 demonstrated that the subjects of B2C mode based logistics distribution include producers, electronic commerce enterprises, logistics center and customers, and the communications between them are managed by e-commerce information management platform [6]. Compared with the traditional logistics distribution structure, the link of the B2C based structure is obviously simpler, and the cost of agricultural products is also greatly reduced because the number of transshipment is greatly reduced. Moreover enterprises can directly receive demand feedback from consumers and adjust the management strategy in time after analysis on the feedback because of the unified management of logistics information.

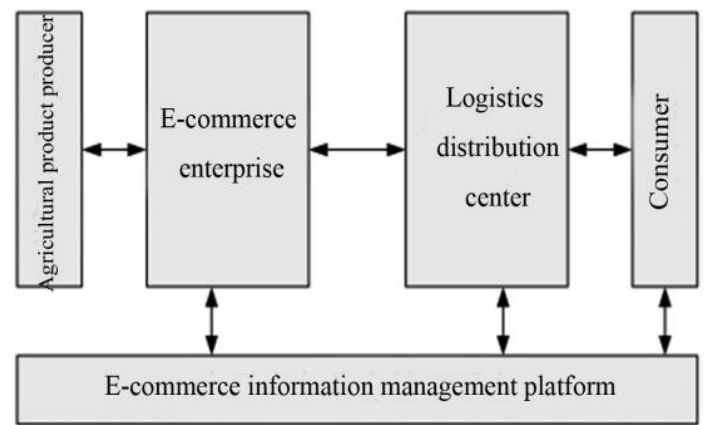

Figure 2: The B2C mode based agricultural products

logistics distribution structure

\section{B2C distribution technology}

Distribution technologies of agricultural products in e-commerce environment are shown in Table 1.

Table 1. Distribution technologies of agricultural products in e-commerce environment

\begin{tabular}{|l|l|}
\hline Distribution technologies & Description \\
\hline Cold-chain logistics technology [7] & $\begin{array}{l}\text { Cold chain refers to a system project which keeps agricultural } \\
\text { products at low temperature in links from output to purchasing. Its } \\
\text { function is to maintain the freshness of foods and reduce food loss. } \\
\text { The specific management content of cold chain includes keeping the } \\
\text { quality and safety of source, extending the storage life of } \\
\text { agricultural products by using proper technologies in processing, } \\
\text { extending the preservation time using automatic refrigeration } \\
\text { storage technology, ensuring excellent transportation technologies } \\
\text { and equipment and ensuring the real-time update of agricultural } \\
\text { food on e-commerce management platform. }\end{array}$ \\
\hline Quality inspection technology [8] & $\begin{array}{l}\text { Currently the standard quality inspection system has not been } \\
\text { established in the production of agricultural products in China; } \\
\text { hence it is difficult to make a reasonable and effective judgment on } \\
\text { agricultural products that need to be transported in logistics } \\
\text { distribution. Therefore, in order to realize basic functions of of B2C } \\
\text { e-commerce platform, i.e., consultation sharing, transaction } \\
\text { connection and information interaction, the government should } \\
\text { learn from international standards or advanced foreign standards to } \\
\text { speed up the construction of agricultural standard system, set up a }\end{array}$ \\
\hline
\end{tabular}




\begin{tabular}{|l|l|}
\hline & $\begin{array}{l}\text { standard monitoring system, and establish a sound international } \\
\text { quality management system and food safety and health certification } \\
\text { system. }\end{array}$ \\
\hline Product traceability technology [9] & $\begin{array}{l}\text { Product traceability technology is applied in the whole process of } \\
\text { agricultural product logistics distribution, including stages of } \\
\text { production and final purchase. Customers can know information of } \\
\text { agricultural products at different stage via the technology. Product } \\
\text { traceability technologies includes sensing technology, perception } \\
\text { and recognition technology, GPS positioning technology, two- } \\
\text { dimensional code technology, etc., among which radio frequency } \\
\text { identification (RFID) has been widely used in quality traceability, } \\
\text { information collection and storage management of agricultural } \\
\text { products in the process of logistics. The technology does not require } \\
\text { manual intervention at work, and can adapt to various working } \\
\text { environments. }\end{array}$ \\
\hline
\end{tabular}

\section{B2C operation flow}

As shown in Figure 3, the first step is purchasing agricultural products from producers, processing agricultural products by enterprises themselves or entrusting a third party and releasing relevant information of the purchased agricultural products on e-commerce information management platform [10]. Then customers put commodities that they want into virtual shopping cart after browsing the information of products on the e-commerce information management platform, input information which is needed in distribution and confirming orders. After receiving the orders from the platform, enterprises will categorize the orders using computers and arrange corresponding commodities. Then the quality of the arranged commodities are inspected. Next transportation temperature is adjusted according to the categories of the commodities. The six step is loading the qualified commodities onto trunks. The seventh step is planning distribution routes according to order requirements. The eighth step is distributing goods according to the planned routes. The ninth step is payment.

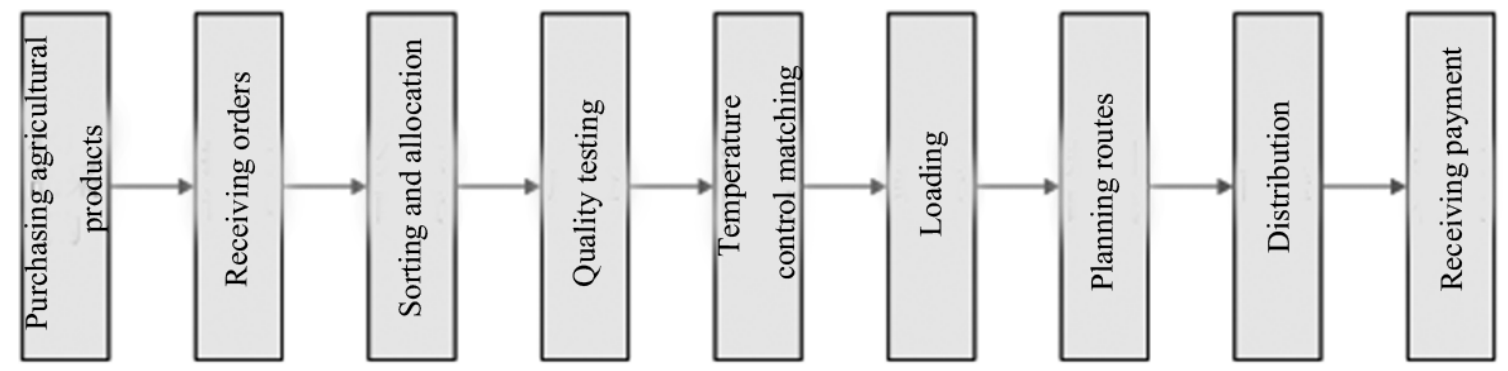

Figure 3: The B2C operation flow of agricultural products

\section{B2C profit pattern}

There are three profit patterns of B2C mode based distribution of agricultural products in ecommerce environment [11]. The first is reducing transaction cost through reducing links in supply chain and logistics distribution cost or using unified purchasing and business accounting. The second is releasing green organic and nuisanceless agricultural products for consumers who have middle or higher income and focusing on long-term brand building, i.e. catering to their pleasure. The third is establishing long-term e-commerce distribution supply chain taking fixed groups such as families, enterprises and hotels as the subjects and making scientific planning to reduce distribution cost.
Moreover the application of cold chain can reduce damage of goods and increase the quality safety and added value of agricultural products.

\section{E-commerce system platform}

The composition of the B2C system platform is shown in Figure 4. The modules are divided into three layers, foreground operation, background operation and decision support. Foreground operation is facing consumers; background operation is facing enterprise operation users; decision support is facing enterprise senior management.

The detailed functions of different modules in the three layers are shown in Table 2. 
Table 2. The modular architecture of the B2C system platform

\begin{tabular}{|c|c|c|}
\hline Level & Function module & Function \\
\hline \multirow[t]{3}{*}{ Foreground operation } & User registration & $\begin{array}{l}\text { Provide functions such as user registration } \\
\text { and information management for users. } \\
\text { Users have rights of query and modifying } \\
\text { their information. }\end{array}$ \\
\hline & Merchandise Query & $\begin{array}{l}\text { After user registration, users can query } \\
\text { related commodity information in their own } \\
\text { interests or query some key information } \\
\text { about commodities. }\end{array}$ \\
\hline & Order management & $\begin{array}{l}\text { Manage, query, modify and print the orders } \\
\text { released by users and feedback the } \\
\text { information which has been processed by the } \\
\text { business department to users. }\end{array}$ \\
\hline \multirow[t]{4}{*}{ Background operation } & Commodity management & $\begin{array}{l}\text { Manage the information of agricultural } \\
\text { products displayed on the website. }\end{array}$ \\
\hline & Order control & $\begin{array}{l}\text { Receive order information and inventory } \\
\text { information, classify according to clients and } \\
\text { importance degree, configure inventory in } \\
\text { different places, and determine delivery time }\end{array}$ \\
\hline & Logistics management & $\begin{array}{l}\text { Here self-distribution, distribution by } \\
\text { producers is discussed. In such a distribution } \\
\text { mode, enterprises will have an accurate } \\
\text { control of logistics information. }\end{array}$ \\
\hline & Settlement management & Support platform capital flow. \\
\hline Decision support & $\begin{array}{l}\text { Market analysis and } \\
\text { prediction }\end{array}$ & $\begin{array}{l}\text { Provide data support for senior decision } \\
\text { makers in enterprises through analyzing } \\
\text { trade information in the platform. }\end{array}$ \\
\hline
\end{tabular}

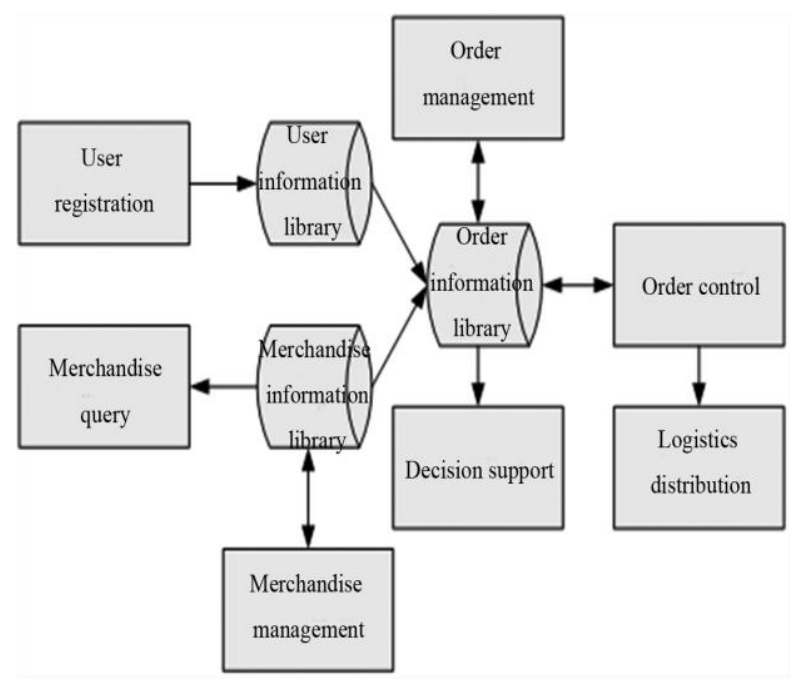

Figure 4: The relationships between different modules of the B2C system platform

\section{B2C Mode Based Route Optimization}

Logistics distribution as the core of B2C distribution mode has an important position. In the the traditional logistics distribution mode, dispatchers mark all delivery places on a map and then classify places which are close or on the same way to the same route [12]. Such a scheduling means will extend distribution distance and cause surplus transport capacity on some routes and insufficient transport capacity on other routes.

\section{Time window}

In addition to meeting the customers' demand for products, the distribution in the electronic business environment must also satisfy the customers' time window requirements, that is, delivery on time. Time windows can be divided into three types: soft, hard and mixed time windows [13]. The relationships between penalty function Q (T) of time windows and time tare shown below.

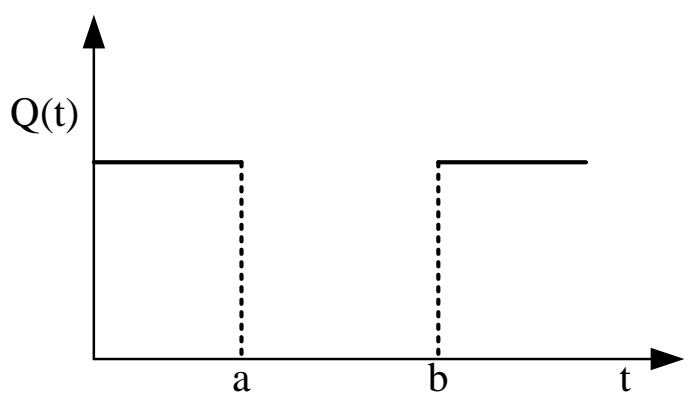

Figure 5: Hard time window

Figure 5 exhibits the relationship between the penalty function of hard time window and time $t$. Hard time window means that goods must be delivered before the prescribed time. 


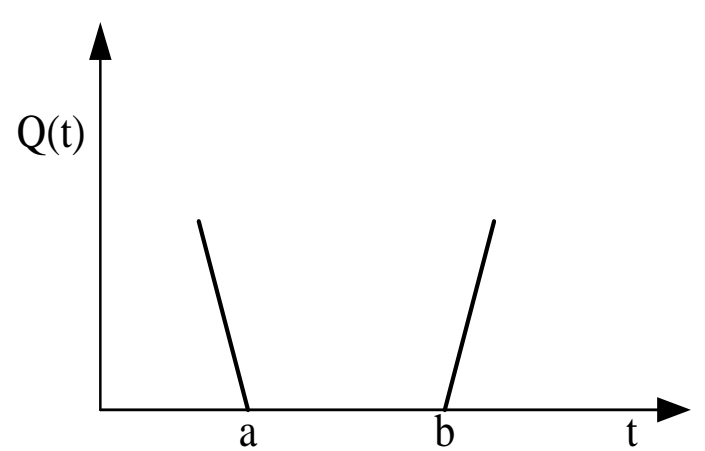

Figure 6: Soft time window

Figure 6 exhibits the relationship between the penalty function of soft time window and time $t$. The requirement of soft time window on the delivery time is looser than hard time window. If goods are not delivered before the specified time, punishment will be given according to the delay time. The degree of punishment is decided by the two parties [14]. Achieving lower delivery cost at the expense of small penalty cost of delay is allowed.

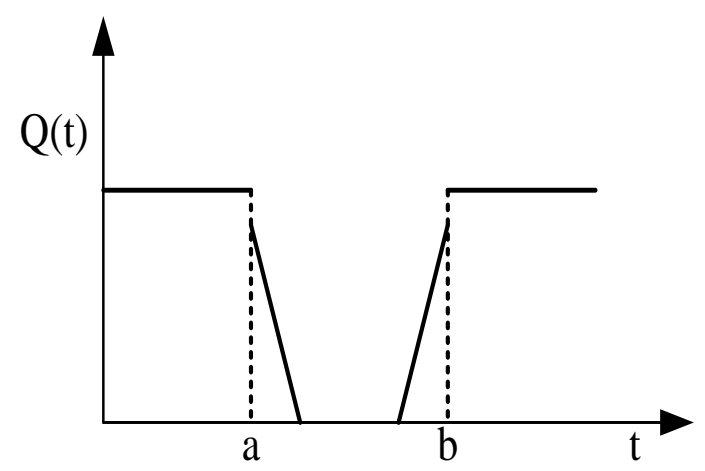

Figure 7: Mixed time window

Figure 7 exhibits the relationship between the penalty function of mixed time window and time $t$. Mixed time window means that delay for some time is allowed, but goods will be rejected if goods are delivered after a specified time point.

\section{Time window constraint based saving algorithm}

Saving algorithm as one of heuristic algorithms can improve the utilization rate of vehicles through scientifically planning distribution routes [15]. Saving algorithm which is featured by simple operation and high calculation speed can greatly shorten transportation distance compared to the traditional algorithms. But transportation cost and delivery time are often neglected due to the excessive emphasis on transport mileage. The basic principle of the algorithm is shortening transportation distance and reduce delivery time through planning the shortest route and reasonably allocate vehicles on the premise of high cargo load factor.
But the delivery time specified by customers needs to be considered in actual application, i.e., time window constraint. The computational formula of time window constraint is:

$$
Y_{b}=X_{a}+Z_{b}+t_{a b}-X_{b}
$$

where $Y_{b}$ stands for the variation of time from point a to point b, $X_{a}$ stands for the earliest time when delivery is completed at point a, $Z_{b}$ stands for the time of completing unloading and other services, tab stands for the time of transportation from point a and $\mathrm{b}$, and $X_{b}$ stands for the latest time when delivery is completed at point $\mathrm{b}$. When $Y_{b}$ is smaller than 0 , it means that vehicles complete tasks before the specified time; when $\mathrm{Yb}$ is equal to 0 , it means that vehicles complete tasks at the specified time; when $\mathrm{Yb}$ is larger than 0 , it means that vehicles complete tasks beyond the specified time. The procedures of formulating distribution routes are as follows. The saved distance between the starting point and destination is calculated using saving algorithm and the table of the shortest distance; then the saved distances are ranked, from large to small. Distribution route is formulated according to the specified time released by distribution center and the ranking table of the saved distances. Then whether networks on the distribution route can satisfy the specified time window is determined by checking departure order. Networks which cannot satisfy time window constraint condition will be excluded one by one until all the networks on the designed route satisfy the constraint condition.

\section{Instance Analysis}

\section{Introduction of the case enterprise}

A Agricultural Development Co., Ltd., (enterprise A for short), was set up in Xi'an, Shaanxi, China, in 2010. It has organic agricultural products sales business in Xi'an. The initial marketing idea of enterprise $\mathrm{A}$ is "from farmland to dining table". It advocates green and environment-friendly life concept and persists in providing safe and natural organic agricultural products to consumers. The company is committed to producing fresh foods at its own production base. To ensure timely delivery of products, the company has established several production bases throughout China. $80 \%$ of the logistics distribution of enterprise $\mathrm{A}$ is completed by the self-support team, and other distribution tasks are completed by other logistics enterprises. The order pattern of enterprise A is instant distribution after purchasing. Self-distribution is mainly carried out in Xi'an, and the delivery time is specified by clients. 


\section{Related distribution information}

Table 3. Order information

\begin{tabular}{|l|l|l|}
\hline $\begin{array}{l}\text { Destination } \\
\text { specified by } \\
\text { customers }\end{array}$ & $\begin{array}{l}\text { Demand }(1 / 2 \\
\text { kilogram) }\end{array}$ & $\begin{array}{l}\text { Time specified } \\
\text { by customers }\end{array}$ \\
\hline A & 500 & $7: 00-16: 00$ \\
\hline B & 600 & $7: 00-10: 00$ \\
\hline C & 600 & $7: 00-16: 00$ \\
\hline D & 1200 & $7: 00-12: 00$ \\
\hline E & 600 & $7: 00-7: 30$ \\
\hline F & 500 & $7: 00-16: 00$ \\
\hline G & 1000 & $7: 00-16: 00$ \\
\hline H & 1000 & $7: 00-10: 15$ \\
\hline I & 700 & $7: 00-8: 00$ \\
\hline J & 800 & $7: 00-13: 00$ \\
\hline
\end{tabular}

Table 4. Matrix of distances between different distribution sites

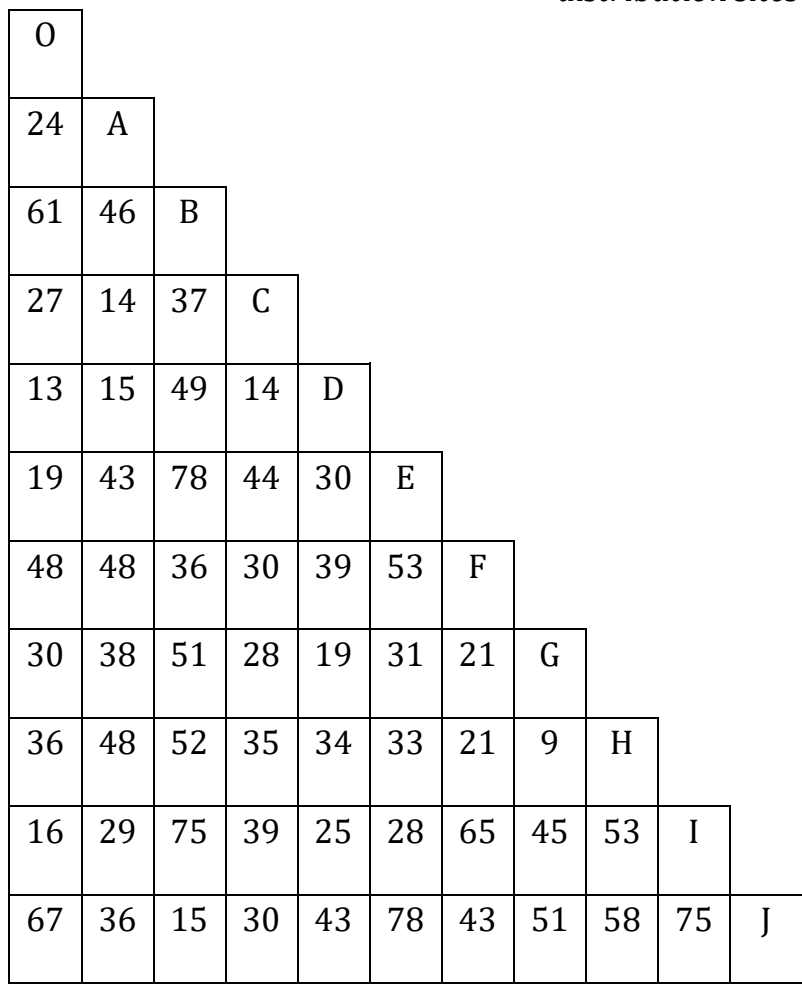

Table 3 shows the order information, which are taken as time window constraint conditions. Table 4 shows the distance between different distribution sites, which are used for creating a table of saved mileage.

Relevant information of logistics distribution department are as follows. The distribution vehicle is a medium cold-chain truck with the maximum loading capacity of $2 \mathrm{t}$ and average transportation speed of $25 \mathrm{~km} / \mathrm{h}$. The truck departures at $6 \mathrm{am}$ every day. The distribution service time is $0.25 \mathrm{~h}$. The freight charge is 250 yuan each time. The oil cost and salary of driver are 3 yuan $/ \mathrm{km}$. The quality of agricultural products produced by enterprise A can satisfy the requirements of customers, and hard time window is used.

\section{Solution of saving algorithm based on hard time window constraint}

The saved mileage between different sites was calculated according to the matrix of distances between different distribution sites shown in Table 4 and then ranked from small to large. Finally a ranking table of the saved mileage is obtained (Table 5).

Table 5. The ranking table of the saved mileage

\begin{tabular}{|l|l|l|l|l|l|}
\hline No. & Route & $\begin{array}{l}\text { Saved } \\
\text { mileage }\end{array}$ & No. & Route & $\begin{array}{l}\text { Saved } \\
\text { mileage }\end{array}$ \\
\hline 1 & BJ & 113 & 24 & AD & 22 \\
\hline 2 & BF & 73 & 25 & DF & 22 \\
\hline 3 & FJ & 72 & 26 & EH & 22 \\
\hline 4 & CJ & 64 & 27 & EG & 18 \\
\hline 5 & FH & 63 & 28 & AG & 16 \\
\hline 6 & FG & 57 & 29 & DH & 15 \\
\hline 7 & GH & 57 & 30 & EF & 14 \\
\hline 8 & AJ & 55 & 31 & AH & 12 \\
\hline 9 & BC & 51 & 32 & AI & 11 \\
\hline 10 & GJ & 46 & 33 & EJ & 8 \\
\hline 11 & BH & 45 & 34 & IJ & 8 \\
\hline 12 & CF & 45 & 35 & EI & 7 \\
\hline 13 & HJ & 45 & 36 & CI & 4 \\
\hline 14 & BG & 40 & 37 & DI & 4 \\
\hline 15 & AB & 39 & 38 & CE & 3 \\
\hline 16 & AC & 37 & 39 & BE & 2 \\
\hline 17 & DJ & 37 & 40 & BI & 2 \\
\hline 18 & CG & 29 & 41 & DE & 1 \\
\hline 19 & CH & 28 & 42 & GI & 1 \\
\hline 20 & CD & 26 & 43 & AE & 0 \\
\hline 21 & BD & 25 & 44 & FI & 0 \\
\hline 22 & AF & 24 & 45 & HI & 0 \\
\hline 23 & DG & 24 & & & \\
\hline
\end{tabular}

The initial distribution route is formulated according to Table 3 and 5 . Then whether different networks can satisfy the time specified by customers are determined according to the time window constraint formula. Networks which cannot satisfy the time window will be removed from the distribution route, and then networks which can satisfy conditions are searched using saving algorithm.

Finally three routes are determined, i.e., (1) $O \rightarrow B \rightarrow F \rightarrow H \rightarrow G \rightarrow C \rightarrow O$,

$O \rightarrow I \rightarrow A \rightarrow J \rightarrow O$ and (3) $O \rightarrow E \rightarrow D \rightarrow O$.

The distribution data of the three routes are shown in Table 6. 
Table 6. Distribution data

\begin{tabular}{|l|l|l|l|}
\hline Distribution route & $(1)$ & $(2)$ & $(3)$ \\
\hline Loading rate/\% & 92.4 & 51 & 44 \\
\hline $\begin{array}{l}\text { Transportation } \\
\text { distance/km }\end{array}$ & 182 & 148 & 63 \\
\hline Freight charge/yuan & 796 & 694 & 439 \\
\hline
\end{tabular}

Table 6 shows that logistics distribution strictly following time window will decrease the average loading rate of vehicles, increase transportation distance, and improve freight cost, leading to increase of distribution cost; distribution cost will be reduced if customers can allow a slight delay of delivery and give corresponding punishment to the delay, i.e., using mixed time window based saving algorithm.

\section{Solution of mixed time window based saving algorithm}

The concept of mixed time window is that customers allow slight delay of goods delivery, but goods will be rejected if the delivery time exceeds a limit. Taking the case mentioned above as an example, if $25 \mathrm{~min}$ of delay is allowed, customers will reject goods if goods are delivered after the limit, and will make economic punishment on the enterprise if goods are delivered within 25 min after delivery time.

The solving steps of mixed time window based saving algorithm were similar to the solving procedures of hard time window based saving algorithm. Firstly the table of saved mileage is edited, i.e., Table 5 . Then the initial distribution route was formulated according to table 5 and constraint conditions. Differing from hard time window based saving algorithm, $\mathrm{Y}_{\mathrm{b}}<0.42$ is defined as executable distribution scheme which satisfies constraints, and unqualified schemes were removed. Then the next qualified network is searched according to the table of saved mileage. When $\mathrm{Yb}$ was between 0 and 0.42 , there is economic punishment, 40 yuan/time in the case mentioned in this study.

Finally two routes were determined, i.e., (1) $O \rightarrow B \rightarrow F \rightarrow H \rightarrow G \rightarrow J \rightarrow O \quad$ and (2) $O \rightarrow E \rightarrow I \rightarrow A \rightarrow C \rightarrow D \rightarrow O$. The related distribution data are shown in Table 7.

Table 7. Distribution data

\begin{tabular}{|l|l|l|}
\hline \multicolumn{1}{|c|}{ Distribution route } & $(1)$ & $(2)$ \\
\hline Loading rate/\% & 98 & 91 \\
\hline $\begin{array}{l}\text { Transportation } \\
\text { distance/km }\end{array}$ & 245 & 117 \\
\hline Freight charge/yuan & 985 & 601 \\
\hline $\begin{array}{l}\text { Economic punishment/ } \\
\text { yuan }\end{array}$ & 40 & 80 \\
\hline
\end{tabular}

Table 7 shows that the transportation routes reduced, but the loading rate of vehicles on the route fully improved, which is because that less vehicles are dispatched. Moreover the total freight also reduced. There is an economic punishment compared to hard time window.

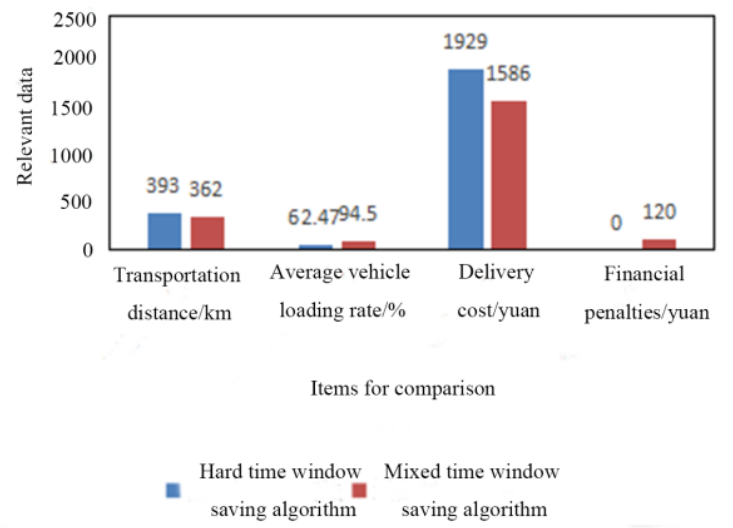

Figure 8: Data comparison between hard time window based saving algorithm and mixed time window based saving algorithm

Figure 8 demonstrates that mixed time window saving algorithm could greatly reduce logistics cost and improve operation efficiency and economic benefits. The transportation distance is optimized by $7.89 \%$, the average loading rate is optimized by $51.27 \%$, and the transportation cost is optimized by $17.78 \%$. But there will be extra economic punishment if schedulers make mistakes. As shown in Table 7 , there is an punishment of 120 yuan. The profit cannot be guaranteed because of the punishment; hence mixed time window should be used with caution.

\section{Conclusion}

With the development of e-commerce, the mode of market trade has gradually transformed from the traditional $\mathrm{C} 2 \mathrm{C}$ e-commerce mode to the $\mathrm{B} 2 \mathrm{C}$ ebusiness mode. Multiple links involving in the traditional distribution logistics of agricultural products short refreshing time of agricultural products will result in the deterioration of agricultural products in the process of transportation and cause economic loss to merchants. Then the transport cost and loss will eventually be reflected in the purchase price of consumers. To solve the problems existing in the traditional logistics distribution of agricultural products, distribution routes were optimized in B2C mode. Moreover saving algorithms based on two time windows were compared and analyzed, taking a real case as an example. It was found that optimizing distribution routes with hard time window based saving algorithm led to low average loading rate, long transportation distance and high freight charge; optimizing distribution routes with mixed time 
window based saving algorithm improved the average loading rate and reduced vehicle number, distance and transportation cost, but there is an economic punishment. The comparison of the optimization effect of the two saving algorithms suggested that mixed time window based saving algorithm is better as it can reduce logistics cost and improve economic benefits. But mixed time window should be carefully used because there will be a loss if schedulers make mistakes.

\section{References}

[1] Zhang J, Wang X, Huang K. "Integrated on-line scheduling of order batching and delivery under B2C e-commerce," Computers \& Industrial Engineering, 2016, 94(C):280-289.

[2] Höglund M, Wikman I. "Collaborative consumption - Business-to-consumer sharing and its economic impact on consumers," Göteborgs Universitetsbibliotek, 2017, 06:274.

[3] Li G, Wang D. “Optimization for the Locations of B2C E-Commerce Distribution Network Based on an Improved Genetic Algorithm," Lecture Notes in Electrical Engineering, 2013, 236:223-232.

[4] Deng C. "A Preliminary Study on the Application of Logistics Distribution Strategy in B2C Ecommerce Enterprises," International Conference on Electronic, Mechanical, Information and Management Society, 2016.

[5] Naccache S, Montreuil B. "Optimizing Consumer Order Delivery Consolidation in Drop-Ship Based B2C Distribution," IFAC Papersonline, 2015, 48(3):1996-2001.

[6] Arnold F, Cardenas I, Sörensen K, et al. "Simulation of B2C e-commerce distribution in Antwerp using cargo bikes and delivery points," European Transport Research Review, 2018, 10(1):2.
[7] Yan Q. "Research on Fresh Produce Food Cold Chain Logistics Tracking System Based on RFID," Advance Journal of Food Science \& Technology, 2015, 7(3):191-194.

[8] Ding Z, Zhang R, Kan Z. “Quality and Safety Inspection of Food and Agricultural Products by LabVIEW IMAQ Vision," Food Analytical Methods, 2015, 8(2):290-301.

[9] Vale T, De Almeida E S, Alves V, et al. "Software product lines traceability," Information \& Software Technology, 2017, 84:1-18.

[10] Liu Z Y, Liu Y, Wang Z W. "Study on the Influence Factors of On-line Shoppers Satisfaction Based on B2C," Technological Development of Enterprise, 2016.

[11] Qadir I, Ali A. "Importance of Logistics Processes for Customer Service and Firm Performance: Evidence from Furniture Industry of Pakistan," 2017, 22(3):27.

[12] Ding R, Huo Y, Wang H. "Game analysis for logistics mode decision of B2C enterprises," Icic Express Letters, 2017, 11(6):1153-1158.

[13] Veenstra M, Cherkesly M, Desaulniers G, et al. "The pickup and delivery problem with time windows and handling operations," Computers \& Operations Research, 2017, 77(7):127-140.

[14] Zare-Reisabadi E, Mirmohammadi S H. "Site dependent vehicle routing problem with soft time window: Modeling and solution approach," Computers \& Industrial Engineering, 2015, 90(C):177-185.

[15] Tang L, Wang W, Wang Y, et al. "An EnergySaving Algorithm with Joint User Association, Clustering and On/Off Strategies in Dense Heterogeneous Networks," IEEE Access, 2017, PP(99):1-1. 